\title{
The Interaction of Market Risk and Idiosyncratic Risk on Equity Mutual Fund Returns
}

\author{
John Murugesu ${ }^{1} \&$ Chandra Sakaran ${ }^{2}$ \\ ${ }^{1}$ Department of Accounting and Finance, HELP University, Kuala Lumpur, Malaysia \\ 2 Department of Business Studies, HELP University, Kuala Lumpur, Malaysia \\ Correspondence: John Murugesu, Department of Accounting and Finance, HELP University, No 15 Jalan Sri \\ Semantan 1, Off Jalan Semantan, Bukit Damansara, 50490, Kuala Lumpur, Malaysia. Tel: 60-3-2716-2000.
}

Received: June 6, 2019

Accepted: July 22, 2019

Online Published: August 8, 2019

doi:10.5430/ijfr.v10n6p1

URL: https://doi.org/10.5430/ijfr.v10n6p1

\begin{abstract}
This study examines the importance of idiosyncratic and systematic risks in explaining equity fund returns in Malaysia. The level of market and idiosyncratic risk in a mutual fund depends on what asset class it invests in. Equity type asset classes are exposed to both systematic and idiosyncratic risk but research generally suggest that only systematic risk is relevant in mutual fund selection since idiosyncratic risk can be reduced through fund diversification. This study attempts to expand the insights of the risk-return relationship by providing additional evidence on the direct and indirect effects of investment risk on equity mutual fund returns. Employing partial least squares structural equation modelling (PLS-SEM), we also explore if idiosyncratic risk moderates the relationship between market risk and mutual fund returns. A sample of 150 Malaysian domestic equity mutual funds comprising of large, mid \& small-cap equity funds were selected from the Morningstar website. The results indicate that market risk does not influence mutual funds returns but idiosyncratic risk has a significant and positive effect. Idiosyncratic risk is proxied by fund characteristics comprising of size, age, expenses and fund manager ability. This study shows that fund size, age or expenses are not significant and only the fund alpha which measures fund manager ability is relevant in predicting fund returns. The study also finds that the fund alpha moderates the influence of market risk on returns by changing the nature of the relationship from positive to negative.
\end{abstract}

Keywords: equity mutual fund returns, idiosyncratic risk, systematic risk, moderating effect

\section{Introduction}

It is generally accepted that higher risks yields higher returns. Hence it is essential for investors to identify their risk preferences and match it with an appropriate fund. This study models the dynamics of idiosyncratic risk, market risk and returns in the Malaysian mutual fund market. Mutual funds or unit trusts as they are commonly referred to in Malaysia provide an opportunity for investors to invest in a diversified portfolio managed by professional managers. An equity fund is a mutual fund that invests primarily in shares of listed companies. Equity funds can be categorized by whether they are domestic (comprise of only Malaysian shares) or international. If domestic, these can be broad market or industry specific funds. Equity funds can be further classified as actively or passively (index fund) managed. Compared to buying shares directly in the stock market, it is generally accepted that mutual fund investments are considered less risky. Inventors in actively managed funds have the added advantage in that they can rely on the fund manager expertise in stock selection and risk reduction. In general, all shares are subject to market risk which cannot be totally eliminated. Nonetheless a fund manager may attempt to reduce unsystematic risk by investing in a portfolio shares from different sectors or geographic regions. Alternatively, lower unsystematic risk can be realised by including bonds and money market instruments within a portfolio. If investments in a portfolio are not perfectly correlated, fund managers can smooth out unsystematic risk elements in a portfolio so that the positive performance of some investments offset the negative performance of others. However, diversification can be a double edged sword. When shares in a portfolio are not positively correlated, this can dilute the upside growth potential during rising markets because below average returns on some investments will lower overall portfolio returns. Therefore a fund manager's stock picking and market timing skills in terms on when to exit the market or rebalancing the portfolio also plays a role in determining fund returns. This study also investigates if actively managed funds earn superior returns. Active funds are managed by professional fund managers and their 
past performance is a matter of public record. The ultimate objective of active management is to reduce portfolio risk and enhance returns. To this end fund managers rely on analytical research to identify mispriced securities and to decide which securities to buy for inclusion in the fund and when to sell. Active fund management is consistent with the notion that markets are not efficient but the information-gathering and analysis efforts of fund managers are. Ippolito (1989) for example shows that if information is costly to acquire then expenses and charges related to mutual funds will be offset by superior returns. This contradicts efficient market theory which states that expenditure on research and trading are wasted because securities prices reflect all available information. In this regard, the existence of weak form market efficiency suggests that fund management is a futile exercise since it is difficult for fund managers to outperform the market. The existence of weak form efficiency is supported by Jensen (1968) who reported that mutual funds returns net of expenses underperformed index funds. Hence, from a risk-return perspective, investors would be better off if they placed their money in an index fund.

The purpose of this study is to develop a model to show which fund risk best predicts equity returns. Specifically the objectives of this study are fourfold. First to determine the relationship between systematic risk and equity funds returns. While the relationship between investor returns and risk has been widely tested for the stock market, the effects of risk on mutual funds is mixed. This study seeks to find out if the positive relationship between stock market risk and returns can be generalized to mutual fund returns. For example portfolio theory states that because investors are risk-averse there is a positive relationship between investment risk and return (Markowitz, 1952). The second objective examines the relevance of idiosyncratic risk in predicting mutual fund performance. There is no general consensus on the significance of idiosyncratic risk in asset pricing and its use to forecast mutual funds returns. The Capital Asset Pricing Model (Sharpe, 1964; Lintner, 1965) argues that only systematic risk is priced in equilibrium since investors can reduce their exposure to idiosyncratic risk by holding a portfolio of assets that are not perfectly positively correlated. A study by Grinblatt and Titman (1989) also document that only systematic risk is important to holders of diversified portfolios. The irrelevance of idiosyncratic risk is further supported in a recent study by Masry \& Menshawy (2018) who show that unsystematic risk measured by individual share price volatility is not a significant predictor of Egyptian stock market returns over the period 2006 to 2015. In contrast some studies show that for incompletely diversified funds, idiosyncratic may still influence returns (Moreno \& Rodriguez, 2013; Kinnunen \& Martikainen, 2017). Liljeblom and Maury (2016) propose that idiosyncratic risk may still affect share returns if companies adopt weak corporate governance practices and have high ownership concentration. Thirdly, the study seeks to explore the moderating effect of idiosyncratic risk on the relationship between systematic risk and mutual funds returns. Stated alternatively, does idiosyncratic risk in terms of actions taken by fund managers increase or reduce the influence of systematic risk on returns? Finally the study examines the efficacy of the Morningstar data as a predictor of mutual fund performance. For mutual fund investors, a fund's past track record plays a critical role in deciding to invest with a particular fund. Perhaps the most daunting challenge facing retail investors in mutual funds is finding a reliable information source to base their investment decision. The difficulty of finding the right source is also linked to the problem of having too much information. Investor's not only face significant costs to acquire data about fund performance but may also lack the ability to process the information. When investors are presented with too much data, it can be difficult to differentiate between what is relevant and what is not. The speed, volume and global reach of information is also making financial markets more efficient. This raises a further issue for investors: To what extent can historical information on risk and return be used to predict mutual funds future performance? If published data on mutual fund performance has information content, it would be useful for investors to know which risk measures are good indicators of fund returns.

The rest of the article is structured as follows. In the next section a literature review on the effects of mutual fund risk on return is discussed and introduces the hypothesis. This is followed by a description of the data used in the research including the method of analysis. The results of the Partial Least Square (PLS) analysis to estimate the effects of risk on mutual funds returns is then presented. The last section concludes the article.

\section{Literature Review}

\subsection{Effect of Market Risk on Returns}

The basic premise of portfolio theory is that investors should only be concerned with market or systematic risk. It is the measure of the volatility of asset prices that affects the overall market. Expanding on portfolio theory, capital asset pricing models further suggest that the risk associated with securities can be divided into systematic (market) risk and idiosyncratic (non-market or specific) risk (Fama \& French, 1993). While idiosyncratic (unsystematic) risk can be diversified away, market risk can only be reduced through hedging or by using the correct asset allocation strategy in stocks, bonds or money market. The goal of asset allocation is to reduce investment risk through the 
selection of the right combination of assets that can provide the highest return potential given the risk tolerance of the investor. Additionally, the Capital asset pricing model suggests that there is a positive linear relationship between market risk premium and return. Early studies by Sharpe (1964) and Grinblatt \& Titman (1989) hold that investors are rewarded for assuming market risk. However studies by Barber (1994) and Lakonishok and Shapiro (1987) find that beta is not a significant predictor of fund returns. Huang et al. (2011) investigate the consequences of risk shifting behaviour by fund managers and document a negative relationship between market risk and fund performance. They suggest that this may be due to the inferior ability of the fund manager or agency conflicts. Studies investigating the effects of portfolio risk on Malaysian mutual funds returns also provide mixed results. Yong and Jusoh (2012) show that higher fund risk results in higher returns for 69 mutual funds in Malaysia for the period 2006 to 2009. The contradictory results above could be explained by risk preferences, asset allocation and market timing skills of the fund manager (Golec, 1996), seasonal variation of returns (Tinic and West, 1984) and if the period of study covered a bear or bull markets (Ma et al., 2018). Mutual fund fees can also distort the positive risk-return relationship. Carhart (1997) document that expense ratios and load fee are both significant and negatively related to mutual fund performance. To test the influence of market risk on mutual fund performance, we propose the following hypothesis:

Hypothesis 1: Market risk has a positive influence on mutual funds returns.

\subsection{Effect of Idiosyncratic Risk on Returns}

The influence of market risk on mutual fund performance has been the primary focuses of empirical research as asset pricing models assume that idiosyncratic risk can be diversified away. While equity mutual fund may hold a large number of stocks, the assumption of risk reduction through diversification has been challenged by a number of researchers. Moreno \& Rodriguez (2013) assess the presence of idiosyncratic risk in actively managed equity funds and conclude that fund portfolios may remain substantially undiversified. Merton (1987) argues that if idiosyncratic risk is not eliminated through diversification then investors should be rewarded with higher returns. This is supported by a recent study on UK mutual funds which shows that idiosyncratic risk is priced in returns and funds with higher levels of alpha, exhibit better market timing and stock selection skills (Garcia et al., 2018). From the above studies it could be inferred that holdings of high-idiosyncratic-risk portfolios may be a deliberate strategy by fund managers to enhance mutual fund performance. Fund managers could adopt beta or alpha strategies in an effort to beat a benchmark index (Duanmu et al., 2018). Alpha strategies are based on the use of research and analysis to identify stocks that are market winners. The beta investment component seeks to increase market returns through changers in asset allocation and rebalancing of portfolio holdings. Fund managers, for example, might want to hold concentrated portfolios in specific industries if they believe some industries will outperform the overall market. If their predictions are accurate, we should observe a positive relation between fund performance and industry concentration. Conversely, if they are wrong, the net asset value of the fund would fall. Based on the above premise, it is hypothesized that:

Hypothesis 2: Idiosyncratic risk has a significant influence on mutual funds

\subsection{Idiosyncratic Risk as a Moderating Variable}

The third hypothesis is motivated by the assumption that investors in actively managed mutual funds tend to be passive in nature since they rely on the fund manager portfolio selection skills. It tests the proposition that a mutual fund manager's diversification strategy or the lack thereof is an important component of the idiosyncratic risk of a fund. This is supported by Huang et al (2011) who suggest that the investment decisions made by a fund manager could influence the risk profile of a fund. If a fund manager's diversification skills are specific to the mutual fund, then the consequences of the investment decisions can affect not only the unsystematic risk of the fund but also influence the funds market risk exposure and returns. For example, if a fund manager expects certain sectors or industries to perform better compared to other, a fund manager may choose to concentrate their portfolio in these sectors to generate a higher alpha (Kacperczyk et al., 2005). These funds face greater idiosyncratic risk compared to larger portfolios due to their lack of diversification. If the fund manager's prediction is correct, the return of these funds is likely to be higher. However if the predictions are wrong, returns would be lower. Market risk could also be higher if these sectors are more susceptible to fluctuations in economic cycles. Alternatively some mutual funds may focus on stocks of small and mid-cap companies to earn higher returns. Smaller companies tend be exposed to higher unsystematic risk due to their higher gearing, limited resources or fewer product lines. While small cap stocks may generate higher returns, their market risk also tends be higher because their shares are less liquid and subject to greater price volatility (Fortin and Michelson, 2005). Funds that invest in stocks from emerging markets may also result in higher unsystematic risk. Emerging market funds may present investors with higher returns. However their returns are also more uncertain due to political instability, exchange controls or if restrictions in repatriation of funds 
are imposed by that country. As a result of these uncertainties, their shares prices tend to be more volatile compared to mature economies (Masry \& Menshawy, 2018). Prior studies have also shown that fund managers can influence the market risk exposure of the fund. While market risk of individual shares cannot be completely eliminated, the market risk of a portfolio can be partially mitigated by the forecasting and asset allocation skills of a fund manager (Golec, 1996). Active managers can adjust their asset portfolios by giving greater weightage to certain sectors and/or stocks relative to the benchmark to beat the market and generate alpha. For example, when the direction of the market is uncertain, fund managers may include in their portfolio shares with a low correlation to smooth out price volatility. Fund managers with superior forecasting ability may also time their equity investments to take advantage of stock market trends (Christoffersen \& Simutin, 2017). When market prices are on an uptrend, a fund portfolio would normally include a greater percentage of high beta stocks to capitalise on the upside potential of the market. Here the relationship between beta and returns is positive. However market conditions can change very quickly, and if prices fall, funds with a high beta would incur greater losses. If a fund manager correctly anticipates the change in market direction, the portfolio could be rebalanced to include low beta stocks as a defense against falling prices. If this strategy is adopted, the fund would have a low beta but high returns relative to the benchmark. Generally low beta portfolios will underperform in strong equity markets, but can outperform high beta portfolios during a bear market (Black et al., 1972). Hence depending on market conditions, fund managers can intentionally manipulate the beta exposure of the fund to consistently provide investors with high returns. The consequence of this strategy if correctly applied is that during a bear market, the relationship between beta and returns would be negative but positive during a bull market. The ability of a fund to outperform the market however assumes that fund managers have the required market timing skills and adopt the right investment strategy. The majority of prior studies however report otherwise. For example, a study by Carhart (1997) showed that actively managed funds underperformed passive funds and found no evidence to support the existence of skilled or informed mutual fund managers. While this may be true for most funds, it does not apply across the board. Grinbelt et al (1993) reports that fund managers that adopted momentum strategies were able to generate positive alphas over the short term. Golec (1996) and Kacperczyk et al (2005) attribute this ability to generate alpha as a sound proxy for investment capability and expertise. In fact some funds charge a load in addition to the annual fee for this skill. An alternative explanation is provided by Gruber (1996) who argues that abnormal returns are possible because a fund managers stock selection skills are not priced in the net asset value and hence some funds may be undervalued. A mutual funds' high idiosyncratic risk exposure may also be a consequence of the fund managers incentives and agency conflicts. Fund managers have an incentive to make investments that increase their remuneration rather than maximize the value as a fund (Chevalier and Ellison, 1999). In summary, given that the expertise of a fund manager is an important driver of the idiosyncratic risk of a fund and that fund managers can apply this skill to influence the beta and returns of a fund, the 3rd hypothesis is formulated as follows:

Hypothesis 3: Idiosyncratic risk moderates the relationship between market risk and returns

\section{Methodology}

\subsection{Theoretical Framework}

Based on the afore-mentioned literature review, the conceptual framework is shown in Figure 1.In this study, the constructs assessed are market risk, idiosyncratic risk and mutual funds returns and examines the interaction of mutual fund risk on returns.

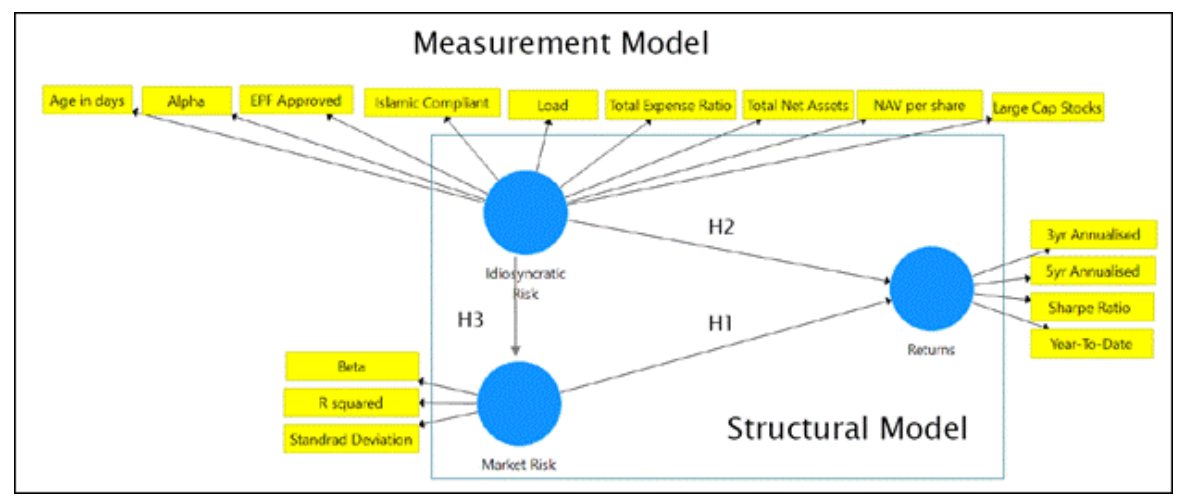

Figure 1. Conceptual framework 


\subsection{Variable Selection}

Sixteen variables are employed divided into 3 categories: market risk, idiosyncratic risk, and mutual fund returns. All the information for the sixteen variables used in this study were obtained from the Morningstar website. In Table 1 below, returns are measured using year-to-date returns for 2017, 3 year annualised returns, 5 year annualised returns and the Sharpe ratio.

Table 1. Mutual fund returns

\begin{tabular}{|l|l|}
\hline Proxy & \multicolumn{1}{c|}{ Explanation } \\
\hline $\begin{array}{l}\text { Year-to-date(YTD), 3 year and 5 } \\
\text { year annualised returns (\%) }\end{array}$ & $\begin{array}{l}\text { Calculated by taking the change in a fund's NAV, assuming the reinvestment of all } \\
\text { income and capital gains distributions (on the actual reinve stment date us ed by the } \\
\text { fund) during the period, and then dividing by the initial NAV. Returns are before } \\
\text { sales charge and load fees and includes both capital appreciation and dividends. }\end{array}$ \\
\hline Sharpe Ratio & $\begin{array}{l}\text { Calculated for the past 36-month period by dividing a fund's annualized returns over } \\
\text { the risk-free rate by its annualized standard deviation. The higher the Sharpe ratio, } \\
\text { the better the fund's hist orical risk-adjusted performance. }\end{array}$ \\
\hline
\end{tabular}

Source: Morningstar

Fund risk is separated into market risk and idiosyncratic risk. In this study, the mutual funds selected are equity funds and hence subject to market risk. These funds tend to be riskier compared to fixed income funds due to the volatility of the stock markets. Since the NAV of equity funds are based on the prices of its underlying securities, the returns generated by equity funds tend to be more volatile compared to fixed income funds. Market risk is operationalised using standard deviation, beta, and R-squared (Table 2). The fund Beta and R-squared measures capture the overall systematic risk of the portfolio while standard deviation measures total risk. Although standard deviation captures both systematic and idiosyncratic risk, for the purpose of this study it is used as a proxy for market risk. Generally most equity mutual funds diversify their portfolio of stocks across different sectors or market segments with the objective to reduce unsystematic risks and generate higher risk adjusted returns. Prior studies have found that a large percentage of unsystematic risk is eliminated if a portfolio holds a modest number of stocks from different sectors. For example Elton and Gruber (1977) showed the 76\% of unsystematic risk is eliminated if a portfolio comprises of 10 stocks from different sectors. If a portfolio increases its holdings to 100 shares, then unsystematic risk is reduced by $84 \%$. Assuming a mutual fund is sufficiently diversified across sectors, then the standard deviation of a fund's portfolio is equivalent to its systematic risk.

Table 2. Market risk

\begin{tabular}{|l|l|}
\hline Proxy & \multicolumn{1}{|c|}{ Explanation } \\
\hline $\begin{array}{l}\text { Standard Deviation of fund } \\
\text { retums (\%) }\end{array}$ & $\begin{array}{l}\text { Measures the total risk (market risk, security-specific risk and portfolio risk) of a } \\
\text { mutual fund. It is calculated using the trailing monthly total returns for the } \\
\text { appropriate time period. All of the monthly standard deviations are then annualized. } \\
\text { When a fund has a high standard deviation, the predicted range of performance is } \\
\text { wide, implying greater volatility. }\end{array}$ \\
\hline Beta of the fund & $\begin{array}{l}\text { Covariance of the return of the fund with the retum of the KL SE composite index (i.e. } \\
\text { KLCI) divided by the variance of the return of the benchmark (KLCI) over a one year } \\
\text { period. It measures the funds volatility relative to the market.A beta above } 1 \text { is more } \\
\text { volatile than the overall market, while a fund with beta below 1 is less volatile and } \\
\text { more suitable for investors seeking lower risk investment. }\end{array}$ \\
\hline R-squared of the fund & $\begin{array}{l}\text { Measures the correlation of the fund's returns to the KLCI. A fund with a low R- } \\
\text { squared indicates the security does not generally follow the movements of the index. }\end{array}$ \\
\hline
\end{tabular}

Source: Morningstar

Table 3 shows the idiosyncratic risk measures used in this study. Idiosyncratic or unsystematic risk in the context of mutual funds is risk unique to the fund. A number of studies have used mutual fund characteristics that capture different aspects of their idiosyncratic risk factors. For example fund characteristics such as size, expenses and age have been used as proxies of idiosyncratic risk (Golec, 1996 \& Soo, 2010). The variables of Net Asset Value per 
share, Total Net Assets, and large-cap stock capture fund size. Fortin and Michelson (2005) find that performance is positively related to fund size. Small/mid cap funds comprise of stocks of small and middle size companies that may have less liquidity than those of larger companies and may be subject to greater price volatility than the overall stock market. In contrast large cap funds generally include shares of large and well established companies with higher trading liquidity and greater access to capital. Additionally, large funds generally have more resources to diversify and have the advantage of spreading their fixed costs over a larger asset base.

Table 3. Idiosyncratic risk

\begin{tabular}{|c|c|}
\hline Proxy & Explanation \\
\hline Alpha $(\%)$ & $\begin{array}{l}\text { The amount by which a fund has out-performed its benchmark, taking into account } \\
\text { the fund's exposure to market risk (as measured by Beta). }\end{array}$ \\
\hline Age (years) & $\begin{array}{l}\text { Calculated based on the number of days since the inception date of the fund to } 31 \\
\text { December } 2017 \text {. }\end{array}$ \\
\hline Total Expense Ratio (\%) & $\begin{array}{l}\text { The percentage of fund assets used to pay for operating expenses and management } \\
\text { fees, including administrative fees, and all other asset-bas ed cos ts incurred by the } \\
\text { fund, except brokerag e costs. }\end{array}$ \\
\hline Load Fee $(\%)$ & $\begin{array}{l}\text { Includes front-end load and/or deferred load fee. It repres ents the sales commis sion } \\
\text { charged to an investor wh buying or redeeming } s \text { hares in a mutualfu nd. }\end{array}$ \\
\hline Net $A$ s set $V$ alve per s hare (RM) & $\begin{array}{l}\text { A fund's net as set value (NAV) represents its per-share price. A fund's NAV is } \\
\text { derived by dividing the totalnet assets of the fund, les s fees and expenses, by the } \\
\text { number of s hares outs tanding. }\end{array}$ \\
\hline Total Net As sets (RM mitlion) & $\begin{array}{l}\text { This figure is recorded in RM millions and repres ents the fund's total as set base. } \\
\text { Us ed to g auge a fund's size and agility }\end{array}$ \\
\hline Large Cap S tocks & $\begin{array}{l}\text { A dummy variable of } 1 \text { if the fund is clas sified a large cap fund or } 0 \text { if it is a s mall or } \\
\text { medium cap fund. }\end{array}$ \\
\hline Islamic Compliant Funds & A dumny variable of 1 if the fund is shariah compliant. \\
\hline EPF A pproved Unit Trust Funds & A dummy variable of 1 if the fund is from an EPF approved unit trust company. \\
\hline
\end{tabular}

The size of a fund is also a proxy for liquidity risk (Chen et al., 2004). Liquidity risk occurs if a fund manager is not be able to exit the market when the share prices fall due to supply exceeding demand. Fund age provides a measure of fund longevity and hence risk. Younger funds have shorter operating histories and tend to aggravate the problem of information asymmetry. Their ratings are also more vulnerable to manipulation (Gregory et al., 1997).Fund expenses are proxied by the expense ratio and sales load. Carhart (1997) found that fund returns are negatively related to expense ratio and load. Risk tends to be higher for funds that charge higher expenses as investors may not be adequately compensated if returns are low. Employee Provident Fund (EPF) approved and Shariah compliant funds are funds that are considered less risky compared to conventional funds and can generate higher returns (Jidwin et al., 2011). These funds are highly regulated by the Malaysian government through the Securities Commission and the Ministry of Finance Malaysia. Only funds with a good track record and stable performance based on the criteria established by the Malaysian Ministry of Finance qualify for this classification. The results of Norman et al (2013) found that shariah-based mutual funds have a lower standard deviation and beta compared to conventional mutual funds. A further aspect of idiosyncratic risk is the experience and expertise of the fund managers to provide superior returns. Golec (1996) shows that the funds manager's ability in terms of stock selection, portfolio rebalancing and diversification strategies can impact a funds risk and performance. This ability is measured by a funds alpha, which measures the excess return of an investment relative to the return of a benchmark index. If a fund manager displays high stock selection ability, the alpha should be positive and significant, reflecting superior performance (Duanmu et al., 2018).

\subsection{Data \& Analysis Technique}

The data used in this study was obtained from the Morningstar website. Morningstar risk ratings and price information are widely used by Malaysian investors and financial advisors to make investment decisions. Its research and recommendations are considered extremely influential by both academics (Del Guercio \& Tkac, 2008) and investors (Foley, 2014) to identify the best funds. For the data on fund returns, the time period of study was from 2013 to 2017. The risk measures were based on cross-sectional data reported for 2017. This data used was disclosed on the Morningstar website as at 31 October 2017. A longer time period was not available as Morningstar only 
provides a maximum of 5 years historical data for returns. Currently, there are 36 mutual funds management companies in Malaysia that manage and distribute mutual funds. As of 31 December 2017, the number of funds launched in Malaysia included 437 conventional funds and 220 Islamic based funds. Of the 657 funds launched in Malaysia, 422 funds were equity funds and the balance comprising of fixed income, money market and balanced funds. Equity funds are generally riskier compared to fixed income funds as they invest almost entirely in equity market where returns tend to be more volatile due to market risk arising from macroeconomic factors such as government regulation, political stability, inflation, tax rates, changes in monetary policy.

The dataset comprised of 150 Malaysian equity mutual funds which included 66 large-cap funds and 84 $\mathrm{mid} / \mathrm{small}$-cap equity funds. Based on the population of 422 equity funds, Morningstar only provided risk and return information for 155 funds. 5 funds were excluded from the sample due to incomplete data resulting in a final sample size of 150 or $36 \%$ of the population. All of the funds used in the study were open-end and actively managed funds. Additionally the funds selected for this study were domestic in nature in that they only invested in the stocks of Malaysian public companies. While domestic funds do not have the foreign exposure to equities that global funds have, they still can achieve diversification for a portfolio by investing in small, mid or large cap stocks. They may also diversify across sectors or focus on a single sector in the economy. Fund managers of domestic funds can also have several different investment objectives, such as emphasis on dividend income or capital gains. Domestic funds tend to be popular with Malaysian investors because they are familiar with the companies in which the fund manager is investing in. In contrast global funds tend to attract less interest as they are subject to higher currency and political risk. Investors in domestic funds normally have a medium to long-term time horizon and therefore their performance will tend to move in line with that of Bursa Malaysia stock market index which is the KLCI. Generally these investors would expect a return that meets or exceeds the KLCI.

The study used Partial Least Square based Structural Equation Modelling (PLS-SEM) to estimate the risk-return model. Past financial studies examining the effects of risk on stocks returns generally relied on econometric methods such as regression analysis to test the relationships between the dependent and independent variables. Two key assumptions underpinning the use of regression analysis is independence of the explanatory variables and that the data is normally distributed. In this study, both of the above assumptions are not made. Hypothesis 3 explores the possibility that idiosyncratic risk moderates the relationship between market risk and returns. Additionally because of the relatively small sample size used in this study, normality is not assumed. A further reason why PLS-SEM is adopted in this study is because idiosyncratic and market risk are viewed as latent variables that affect fund returns. One of the main motivations in using PLS-SEM is to model the relationships between latent variables. For example we cannot directly observe idiosyncratic risk of a fund, however we can observe the consequences of a fund managers stock selection skills from the funds alpha, size, age and expenses. By including these measurable items rather than the composite score and modelling items as indicators of idiosyncratic risk, we are able to assess its relationship with the other two latent variables comprising of market risk and return. A further advantage of using latent variables is that they can be aggregated in a model to represent an underlying concept, making it easier to identify the key drivers of a construct (Hair et al., 2014). An alternative to using PLS-SEM is the covariance-based SEM (CB-SEM). In comparing the two methods, PLS-SEM uses ordinary least squares (OLS) regression as its estimation procedure compared to the maximum likelihood (ML) estimation procedure for (CB-SEM). The two methods are similar but PLS-SEM has some distinct advantages over CB-SEM. Firstly because it is a non-parametric statistical method, it does not require the data to be normally distributed or for the sample to be large. Secondly, PLS-SEM makes no assumptions about the normality of the data and it can handle constructs measured with single and multi-item measures (Cassel, Hackyl, and Westlund, 1999). When deciding which method to employ, PLS -SEM is more appropriate if the theory underlying the model is not well defined and the objective is prediction and explanation of target constructs. However if the goal is verification of existing theory, then CB-SEM would be considered more suitable (Hair et al., 2014). Based on the objectives of this study and sample size, the PLS-SEM method is selected as the more suitable method. The model proposed in this study assumes that Malaysian mutual funds returns are a function of market risk and idiosyncratic risk. The model also explores the possibility that idiosyncratic risk arising from the fund managers' stock selection skills can influence the relationship between the funds market risk and returns. The model is analyzed using the SmartPLS 3.0 software and interpreted in two stages: firstly, the assessment of the reliability and validity of the measurement model and secondly, the assessment of the structural model. 


\section{Results}

\subsection{Descriptive Statistics}

Table 4 presents the descriptive statistics for the indicators used in the study. For the period January 2013 to December 2017 the performance of the Malaysian stock market was rather flat with Kuala Lumpur Composite Index (KLCI) providing annualised returns of $2.18 \%$. A sideways drift in stock markets is a difficult environment for investors to make a profit as they are unsure in which direction the market will move. During buoyant market conditions, shares with a high beta, R-squared and standard deviation are expected to provide high returns while the converse applies during weak conditions (Kothari and Warner, 1997). The mutual funds in the sample recorded average returns before expenses and loads of $6.54 \%$ pa. Fund expenses and load fees averaged $1.38 \%$ and $5.24 \%$ respectively. Therefore after expenses and load fee, the average fund returns were less than zero and underperformed the index. In terms of risk adjusted returns, the average value of the Sharpe ratio was 0.06 . As the value is close to zero, average returns were close to the risk-free rate. The sample data furthers indicates an average beta value and R-squared of 0.91 and $70.30 \%$ respectively. A high beta and R-squared are indicative of fund returns being more sensitive to market swings. Hence the high beta and R-squared values reported suggest that the sample tend to move in line with the KLCI benchmark index.

Table 4. Descriptive statistics

\begin{tabular}{|l|r|r|r|r|r|r|}
\hline & Frequency & $\%$ & Average & $\begin{array}{r}\text { Standard } \\
\text { Deviation }\end{array}$ & Maximum & Minimum \\
\hline Type of Funds & & & & & & \\
\hline EPF Approved \& Shariah Compliant Funds & 104 & $69 \%$ & & & & \\
\hline Conventional Funds & 46 & $31 \%$ & & & & \\
\hline Total & 150 & $100 \%$ & & & & \\
\hline Market Capitalisation & & & & & & \\
\hline Large Cap Funds & 65 & $43 \%$ & & & & \\
\hline Mid/Small Cap Funds & 85 & $57 \%$ & & & & \\
\hline Total & 150 & $100 \%$ & & & & \\
\hline Variables & & & & & & \\
\hline Standard Deviation of fund returns (\%) & & & 9.52 & 11.90 & 146.84 & 0.00 \\
\hline Beta of the fund & & & 0.91 & 0.87 & 10.57 & 0.00 \\
\hline R-squared of the fund & & & 70.30 & 27.05 & 94.43 & 0.00 \\
\hline Alpha (\%) & & & 0.20 & 6.26 & 65.17 & $(11.47)$ \\
\hline Age (years) & & & 15.52 & 10.48 & 50.38 & 0.76 \\
\hline Total Expense Ratio (\%) & & & 1.38 & 0.75 & 3.21 & 0.00 \\
\hline Load Fee (\%) & & & 5.24 & 1.72 & 7.00 & 0.00 \\
\hline Net Asset Value per share (RM) & & & 0.66 & 0.45 & 3.33 & 0.11 \\
\hline Total Net Assets (RM million) & & & 379 & 883 & 5896 & 0.00 \\
\hline Year-to-date(YTD) returns (\%) & & & 5.64 & 9.41 & 54.24 & $(16.49)$ \\
\hline 3 year annualised returns (\%) & & & 4.12 & 5.34 & 46.35 & $(7.59)$ \\
\hline 5 year annualised returns (\%) & & & 6.54 & 4.53 & 24.51 & $(0.73)$ \\
\hline Sharpe ratio & & & 0.06 & 0.34 & 0.86 & $(0.96)$ \\
\hline Returns from KLCI index (\%) & & & 2.18 & 3.63 & 8.40 & $(0.75)$ \\
\hline
\end{tabular}

For the period under review, the KLCI increased by $2.18 \%$ pa on average. Given a beta of 0.91 , the sample would be expected to provide a return of $1.98 \%$. Compared to expected returns, the actual performance of mutual funds for the sample period was not impressive. With an average 5 year annualised returns of 6.54 , expense ratio of $1.38 \%$ and load of $5.24 \%$, the funds in this study provided a return of $-0.08 \%$ which underperformed the KLCI. This could be to the sales load and annual management fees that active funds charge are usually significantly higher compared to index funds. Additionally some of the funds generated large positive alphas during the study period but on average the alpha value was close to zero. A high alpha fund is indicative of the skills of the fund manager to provide superior returns. Alternatively the high alpha of some of the funds may also be partly due to the home country bias of the fund 
manager or because the fund is focused on a specific sector that performed well. In terms of frequency, 61 out 150 funds in the sample recorded an alpha of 0 or higher. Based on the premise that the efficient market hypothesis is correct, active fund management is non-productive. However, since $40 \%$ of funds in the sample managed to beat the KLCI benchmark index, this suggests that some fund managers were indeed successful in their stock picking ability to enhance fund returns.

\subsection{Assessment of the Measurement Model}

In Figure 1 the latent constructs of idiosyncratic risk, market risk, and returns are designed with reflective indicators as the arrows were pointing towards their respective indicators. In utilizing a PLS path modeling technique, a two-step procedure is performed in structural equation modeling (SEM). In the first step, the measurement model is first evaluated for consistency and validity of the variables. In this study, consistency is evaluated based on individual item reliability and construct reliability tests while the validity of the variables is based on convergent and discriminant validity. First the individual item reliability is assessed by examining the outer loadings of each variable to their respective constructs. In Smart Pls the outer loadings are computed for all measurement model constructs in the path model. High outer loadings for a variable indicate that the associated variables are good measures of the construct. A measurement model is said to have satisfactory indicator reliability when each item's loading is at least 0.708 (Hair et al., 2014). The other parameter of consistency is construct reliability and this is evaluated using Cronbach's alpha and Composite Reliability. Finally, convergent validity is assessed by the average variance extracted (AVE) value. For the model is to be considered adequate, Hair et al. (2014) suggests that the value for all three measures should be higher than a threshold value of 0.7. Based on the above criteria, the measurement model is assessed by an iterative process to remove the weak variables from the model. For the first iteration, the outer loading for each factor is computed in the PLS path model. Any factor with a loading of less than 0.7 is removed if it leads to an increase in the average variance extracted (AVE) value, and the model is run again. Once all of the variables have a loading of greater than 0.7 , the measurement model is considered reliable. Table 5 below summarizes the first and final iteration.

Table 5. Estimates of the initial and final measurement model

\begin{tabular}{|c|c|c|c|c|c|c|c|c|c|}
\hline \multirow[b]{2}{*}{ Constructs } & \multirow[b]{2}{*}{ Items } & \multicolumn{4}{|c|}{ First Iteration } & \multicolumn{4}{|c|}{\begin{tabular}{|c|} 
Final Iteration \\
\end{tabular}} \\
\hline & & Loadings & \begin{tabular}{|l} 
Aver age \\
Variance \\
Extr acted \\
(AVE)
\end{tabular} & $\begin{array}{l}\text { Composite } \\
\text { Reliability } \\
\text { (CR) }\end{array}$ & $\begin{array}{l}\text { Cronbach's } \\
\text { Alpha(CA) }\end{array}$ & Londings. & \begin{tabular}{|l} 
Aver age \\
Variance \\
Exracted \\
(AvE)
\end{tabular} & $\begin{array}{l}\text { Composite } \\
\text { Reliability } \\
\text { (CR) }\end{array}$ & $\begin{array}{l}\text { Cronbac h's } \\
\text { Alpha(CA) }\end{array}$ \\
\hline \multirow[t]{3}{*}{ Mark et Risk } & Beta & 0.997 & \multirow[t]{3}{*}{0.676} & \multirow[t]{3}{*}{0.837} & \multirow[t]{3}{*}{0.696} & 0.995 & \multirow[t]{3}{*}{0.991} & \multirow[t]{3}{*}{0.995} & \multirow[t]{3}{*}{0.991} \\
\hline & R Squared & 0.253 & & & & omitted & & & \\
\hline & Standard Deviation & 0.984 & & & & 0.995 & & & \\
\hline \multirow[t]{9}{*}{$\begin{array}{l}\text { Id osyncr atic } \\
\text { Risk }\end{array}$} & Age in Days & 0.049 & \multirow[t]{9}{*}{0.138} & \multirow[t]{9}{*}{0.093} & \multirow[t]{9}{*}{0.070} & omitted & \multirow[t]{9}{*}{1.000} & \multirow[t]{9}{*}{1.000} & \multirow[t]{9}{*}{1.000} \\
\hline & Alpha & 0.837 & & & & 1.00 & & & \\
\hline & EPF Approved & 0.251 & & & & omitted & & & \\
\hline & Islamic Compliant & -0.233 & & & & omitted & & & \\
\hline & Load & -0.416 & & & & omitted & & & \\
\hline & Tota1 Expense ratio & -0.118 & & & & omitted & & & \\
\hline & Large Cap Stocks & 0.348 & & & & omitted & & & \\
\hline & NAV per share & 0.310 & & & & omitted & & & \\
\hline & Tota1 Net A sse ts & -0.137 & & & & omitted & & & \\
\hline \multirow[t]{4}{*}{ Returns } & Year to date & 0.525 & \multirow[t]{4}{*}{0.606} & \multirow[t]{4}{*}{0.856} & \multirow[t]{4}{*}{0.771} & omitted & \multirow[t]{4}{*}{0.746} & \multirow[t]{4}{*}{0.898} & \multirow[t]{4}{*}{0.832} \\
\hline & 3 yr Annualised & 0.859 & & & & 0.914 & & & \\
\hline & 5 yrAnnualised & 0.848 & & & & 0.796 & & & \\
\hline & Shampe Ratio & 0.831 & & & & 0.877 & & & \\
\hline
\end{tabular}

In Table 5 the idiosyncratic risk variables comprising of the Age in Days, EPF Approved, Islamic Compliant, Sales Load, Expenses ratio, Large Cap Stocks, NAV per share and Total Net Asset Value are removed from the initial model since their outer loadings are less than the above recommended values. Additionally, the $\mathrm{R}$ squared variable 
which captures the market risk construct and year to date returns are omitted for the same reason. In the final model as shown Table 5, the market risk construct is measured by standard deviation and beta and idiosyncratic risk proxied by alpha. The unit trust returns construct is measured using the Sharpe ratio, 3 year and 5 year annualised returns. The final measurement model above shows that all the variable outer loadings, Composite reliability, Cronbach's alpha and AVE are above the recommended level of 0.7 indicating adequate consistency and convergent validity. The final model further shows that only alpha remains as a measure of idiosyncratic risk and that the variables R squared and year-to-date returns have been removed from the final model. Discriminant validity is assessed using the Fornell and Larcker's criterion. The Fornell-Larcker criterion states that the square root of each construct's AVE should be greater than its highest correlation with any other construct.

Table 6 indicates the above criterion is satisfied with respect to all the constructs. In Table 6, the square root of the AVE for idiosyncratic risk, market risk, and returns are the diagonal values of 1, 0.995 and 0.864 respectively. The non-diagonal values represent the correlations $(R)$ between the latent variables. Since the square root of the AVE for idiosyncratic risk is higher than its correlation values with market risk and returns of 0.815 and 0.807 respectively, the Fornell-Larcker criteria is met. The above criterion is also satisfied with respect to market risk and return constructs. In sum, the measurement model demonstrated adequate consistency, convergent validity, and discriminant validity and is valid and fit to be used to estimate the parameters in the structural model.

Table 6. Fornell-Larker criterion

\begin{tabular}{|l|r|r|r|}
\cline { 2 - 4 } \multicolumn{1}{c|}{} & Idiosyncratic Risk & Market Risk & Returns \\
\hline Idiosyncratic Risk & 1 & & \\
\cline { 2 - 4 } Market Risk & 0.815 & 0.995 & \\
\cline { 2 - 4 } Returns & 0.807 & 0.478 & 0.864 \\
\hline
\end{tabular}

\subsection{Assessment of the Structural Model}

The results of the structural model are provided in Table 7. The structural model is assessed by estimating the coefficient of determination $\left(\mathrm{R}^{2}\right)$ and the significance of the path coefficient values $(\beta)$ after performing bootstrapping. For a good model, Cohen et al. (1992) suggests an $\mathrm{R}^{2}$ value of 0.25 or higher. Additionally, Hair et al., (2014) suggest that an acceptable t-value for a two-tailed test is 1.96 (significance level of 5 percent). Results from Table 7 show that the effect of idiosyncratic risk on returns is positive and significant with a t-value greater than 1.96. The results further indicate that market risk has a positive influence but its effect on returns it is not significant. The primary goal of the PLS-SEM model in this study is using risk to predict mutual fund returns. The higher the $\mathrm{R}^{2}$ value the better the prediction of the PLS path model. The model has an $R^{2}$ value of 0.75 indicating that the explanatory power of unsystematic risk on returns is good. A possible explanation for the irrelevance of market risk above is provided by Jegadeesh and Titman (1993). They found that the abnormal share returns are not due to their systematic risk or to delayed stock price reactions to external factors. Instead they are more likely due to momentum strategies adopted by investors. For example, shares that have performed well in the past are more likely to catch the attention of fund managers for inclusion in the fund portfolio. The higher demand for these shares will cause their price to increase in the short term. However over the medium to longer term the price increase will reverse out when their price gets too high. This causes demand to fall and the price will revert to a lower average value. If the assumption of share price mean-reversion is correct, this implies that it easier for funds to outperform the market in the short term but over the medium to long term, their performance will decline. Hence the market timing skills of fund managers are crucial.

Table 7. Path coefficients

Results After Bootstrapping
\begin{tabular}{|c|l|c|c|c|c|l|}
\hline Hypothesis & Path & $\begin{array}{c}\text { Path } \\
\text { Coefficients }\end{array}$ & $\begin{array}{c}\text { Standard } \\
\text { Deviation }\end{array}$ & T Statistic & p Value & Results \\
\hline 1 & Matket Risk $>$ Returns & 0.535 & 0.379 & 1.414 & 0.158 & Not Significant \\
\hline 2 & Idiosyncratic Risk $>$ Retums & 1.243 & 0.252 & 4.936 & 0.000 & Significant \\
\hline
\end{tabular}

R- $0.86, R^{2}-0.748$ 


\subsection{Moderating Effect of Idiosyncratic Risk}

This study also examines if the association between markets risk and mutual funds returns is moderated by idiosyncratic risk. In other words, it affects the relationship between the independent variable or predictor variable and a dependent variable or criterion variable. It is proposed that idiosyncratic risk changes the strength and/or the direction of the relationship between market risk and returns. In this study, exposure to alpha is equivalent to exposure to idiosyncratic risk. The moderating effect is first tested assuming idiosyncratic does not moderate market risk and then on the assumption that it does. In Table 7, without the moderating effect of idiosyncratic risk, market risk has no significant effect on returns but idiosyncratic risk does. Table 8 shows the moderating effect of idiosyncratic risk. It indicates that the alpha risk measure is both significant and positive. Additionally alpha has a significant moderating effect on the relationship between market risk and returns ( $p$-value $=0.043$ ). The indirect effect of idiosyncratic risk on returns is significant and negative (Path Coefficient=-0.133) with higher market risk leading to lower returns. In contrast, the direct effect of market risk on mutual funds returns is positive but not significant (Path Coefficient=0.366).

Table 8. Moderating effect of idiosyncratic risk on market risk

\begin{tabular}{|l|r|r|r|r|r|}
\hline Path Coefficients after Bootstrapping \\
\hline & $\begin{array}{c}\text { Path } \\
\text { Coefficients }\end{array}$ & $\begin{array}{c}\text { Sample } \\
\text { Mean }\end{array}$ & $\begin{array}{c}\text { Standard } \\
\text { Deviation }\end{array}$ & t Statistic & p Value \\
\hline Idiosyncratic Risk - Returns & 1.581 & 1.5 & 0.423 & 3.736 & 0.001 \\
\hline Market Risk -> Returns & 0.366 & 0.334 & 0.213 & 1.718 & 0.086 \\
\hline Moderating Effect 1 -> Returns & -0.133 & -0.171 & 0.067 & 1.975 & 0.043 \\
\hline
\end{tabular}

Therefore, the indirect effect of idiosyncratic risk has changed the nature of the market risk-return relationship from positive to negative. The above results suggest that fund managers portfolio selection strategies are effective in reducing beta risk or volatility exposure while increasing alpha performance. To better understand the above results, it should be highlighted that for the period under review, the Malaysian stock market was going through a sideways drift with prices fluctuating within a tight range and for an extended period. When the direction of the market is uncertain and if a fund manager expects prices to fall in the short term, a fund manager could in theory construct a zero beta portfolio or zero systematic risk to provide investors with better returns. Such a portfolio would have zero correlation with market movements and have the same expected return as the risk-free rate. If market risk is defined in terms of price volatility, then adding stocks with a low beta to a portfolio in a downward trending market can decreases market risk when compared to higher-beta portfolios. Low beta portfolios act as a buffer against falling markets and can outperform high beta funds. Under these markets conditions, market risk has a negative relationship with return. Conversely when share market prices are on the rise, funds with a high alpha and high beta would also provide funds with superior returns. Here beta has a positive relationship with returns. To construct such a portfolio however would depend largely on the fund managers' stock selection and market timing ability or its proxy of alpha as used in this study. Therefore the moderating effect of alpha on the direction of the relationship between market risk and returns would also depend on market conditions. In summary the results show that alpha is the only significant measure of idiosyncratic risk while mutual fund size, expenses, age are unrelated to returns. Market risk does not appear to influence fund returns. Additionally, beta risk is negatively associated with returns if alpha is present.

\section{Conclusion}

The results of the study indicate that over the medium term, mutual funds generally tend to underperform the market index due to fund expenses. This is generally the same trend with other overseas markets where the number of active mutual funds that outperform the market tends to decrease as the period of time lengthens. It may well be easier for mutual funds to outperform the market in the short term and during bear markets. The study reports that only alpha risk has a significant effect on mutual funds returns for the study period. Under weak market conditions, excess returns for investors in Malaysian mutual funds are less dependent on market sentiment and fund characteristics but more on the fund alpha. Overall the results suggest that Malaysian fund managers are able to generate significant and positive alphas by diversifying portfolios to reduce unsystematic risk. The results further show that alpha has a moderating effect between market risk and fund returns. Therefore if funds are able to generate positive alphas, they 
are more likely to have lower market risk and higher returns. While market risk cannot be eliminated, the key issue for fund managers is how to mitigate these risks without significantly impacting the performance of the fund. If there is a limited relationship between market risk and returns as suggested by Fama \& French (1992), the results suggest that the fund manager's expertise and investment capability in portfolio selection can increase returns without necessarily increasing market risk by the same magnitude. Unpredictable and volatile market conditions present a problem to fund managers as to when they should enter and exit. Hence market timing skills in terms of moving into and out of the markets and the ability to predict trend reversals correctly are crucial to achieving high returns for open-ended funds. Assuming the alpha risk measure correctly predicts fund managers ability to outperform the market, the results of this study indicate that investors can use the alpha to judge fund performance. Under weak market conditions, a positive beta may not be enough to avoid losses but the discretionary ability of fund managers to generate alpha in the fund could turn these losses into positive returns. For emerging markets such as Malaysia where stock markets are not fully efficient, the results indicate that fund managers can use their expertise to identify mispriced stocks in the market. For equity funds that are actively managed, investors should seek out funds with a high alpha. These are funds where the fund managers have a good track record of managing risk, stock selection, and market timing skills since these characteristics are associated with superior returns.

\section{References}

Barber, J, R. (1994). Mutual Fund Risk Measurement and Future Returns. Quarterly Journal of Business and Economics, 33(1), 55-64. https://doi.org/10.1016/S1057-0810(97)90004-4

Black, F., Jensen, M, C., \& Scholes, M. (1972). The Capital Asset Pricing Model: Some Empirical Tests, Studies in the Theory of Capital Markets. New York: Praeger.

Carhart, M. (1997). On Persistence in Mutual Fund Performance. Journal of Finance, 52(1), 57-82. https://doi.org/10.2307/2329556

Cassel, C., Hackl, P., \& Westlund, A.H. (1999). Robustness of Partial Least Quares Method for Estimating Latent Variable Quality Structures. Journal of Applied Statistics, 26(4), 435-446. https://doi.org/10.1080/02664769922322

Chen, J., Hong, H., Huang, M., \& Kubik, J.D. (2004). Does Fund Size Erode Mutual Fund Performance? The role of Liquidity and Organization. American Economic Review, 94(5), 1276-1302. https://doi.org/10.1257/0002828043052277

Chevalier, J., \& Ellison, G. (1999). Are some Mutual Fund Managers better than others? Cross-Sectional Patterns in Behavior and Performance. Journal of Finance, 54(3), 875-899. https://doi.org/10.1111/0022-1082.00130

Christoffersen, E. K., \& Simutin, M, (2017). On the Demand for High-Beta Stocks: Evidence from Mutual Funds. Review of Financial Studies, 30(8), 2596-2620. https://doi.org 10.1093/rfs/hhx022.

Cohen, J. (1992). A Power Primer. Psychological Bulletin, 112(1), 155-159. http://dx.doi.org/10.1037/0033-2909.112.1.155

Del Guercio, D., \& Tkac, P.A. (2008). Star Power: The Effect of Morningstar Ratings on Mutual Fund Flow. Journal of Financial \& Quantitative Analysis, 43(4), 907-936. https://doi.org/10.1017/S0022109000014393

Duanmu, J., Malakhov, A., \& McCumb, W.R., (2018). Beta Active Hedge Fund Management. Journal of Financial and Quantitative Analysis, 53(6), 2525- 2558. https://doi.org/10.1017/S0022109018000388

Elton, E. J., \& Gruber, M. J. (1977). Risk Reduction and Portfolio Size: An Analytical Solution. The Journal of Business, 50(4), 415-37. http://dx.doi.org/10.1086/295964

Fama, E., \& French, K. (1993). Common Risk Factors in the Returns on Stocks and Bonds. Journal of Financial Economics, 33(1), 3-56. https://doi.org/10.1016/0304-405X(93)90023-5

Fama, E. F., \& French, K. (1992). The Cross-Section of Expected Stock Returns. Journal of Finance, 47, 427-65. https://dx.doi.org/10.2139/ssrn.2511246

Foley, S. (2014, August 18). A Force to be Reckoned With. The Financial Times (p. 7). Retrieved from https://www.ft.com/content/e02d2768-22d2-11e4-8dae-00144feabdc0

Fortin, R., \& Michelson, S. (2005). Active International Mutual Fund Management: Can Managers Beat the Index?. Managerial Finance, 31, 41-51. https://doi.org/10.1108/03074350510769451

García, J. V., Marta, V., Boubaker, S., \& Manita, R. (2018). Idiosyncratic Risk and Mutual Fund Performance. Annals 
of Operation Research. https://doi.org/10.2139/ssrn.2354177

Golec, J. H. (1996). The Effects of Mutual Fund Managers' Characteristics on their Portfolio Performance, Risk, and Fees. Financial Services Review, 5(2), 133-48. https://doi.org/10.1016/S1057-0810(96)90006-2

Gregory, A., Matatko, J., \& Luther, R. (1997). Ethical Mutual funds Financial Performance: Small Company Effects and Fund Size Effects. Journal of Business Finance \& Accounting, 24(5), 705-725. https://doi.org/10.1111/1468-5957.00130

Grinblatt, M., \& Titman, S. (1989). Mutual Fund Performance: An Analysis of Quarterly Portfolio Holdings. The Journal of Business, 62(3), 393-416. https://doi.org/10.1086/296468

Grinblatt, M., Titman, S., \& Wermers, R. (1995). Momentum Investment Strategies, Portfolio Performance, and Herding: A Study of Mutual Fund Behavior, American Economic Review, 85(5), 1088-1105.

Gruber, M. J. (1996). Another Puzzle: The Growth in Actively Managed Mutual Funds. Journal Finance, 51(3), 783-810. https://doi.org/10.1111/j.1540-6261.1996.tb02707.x

Hair, J. F., Hult, G. T. M., Ringle, C. M., \& Sarstedt, M. (2014). A Primer on Partial Least Squares Structural Equation Modeling (PLS-SEM). Los Angeles: SAGE Publication, Inc.

Huang, J., Sialm, C., \& Zhang, H. (2011). Risk Shifting and Mutual Fund Performance. The Review of Financial Studies, 24(8), 2575-2616. https://doi.org/10.1093/rfs/hhr001

Ippolito, R, A. (1989). Efficiency with Costly Information: A Study of Mutual Fund Performance, 1965-1984. Quarterly Journal of Economics, 104(1), 1-23. https://doi.org/10.2307/2937832

Jegadeesh, N., \& Titman, S. (1993). Returns to Buying Winners and Selling Losers: Implications for Stock Market Efficiency. The Journal of Finance, 48(1), 65-91. https://doi.org/10.1111/j.1540-6261.1993.tb04702.x

Jensen, M. C. (1968). The Performance of Mutual Funds in the Period 1954-1964. Journal of Finance, 23(2), 389-416. https://doi.org/10.1111/j.1540-6261.1968.tb00815.x

Jidwin, A. P., Tuyon, J., \& Ali, R. (2011). The Malaysian Employees Provident Fund's Members' Investment Scheme: Survey of Fund Selection, Performance and Perceptions. Asia-Pacific Management Accounting Journal, 6(1), 47-79.

Kacperczyk, M., Sialm, C., \& Zheng, L. (2005). On the Industry Concentration of Actively Managed Equity Mutual Funds. Journal of Finance, 60(4), 1983-2012. https://dx.doi.org/10.2139/ssrn.353420

Kinnunen, J., \& Martikainen, M. (2017). Expected Returns and Idiosyncratic Risk: Industry-Level Evidence from Russia. Emerging Markets Finance \& Trade, 53, 528-2544. https://doi.org/10.1080/1540496X.2016.1210509

Kothari, S. P., \& Warner, J. B. (1997). Measuring Long-Horizon Security Price Performance. Journal of Financial Economics, 43(3), 301-339. https://doi.org/10.1016/S0304-405X(96)00899-9

Lakonishok, J., \& Shapiro, A. C. (1987), Systematic Risk, Total Risk, and Size as Determinants of Stock Returns. Journal of Banking and Finance, 10(1), 115-132. https://doi.org/10.1016/0378-4266(86)90023-3

Liljeblom, E., \& Maury, B. (2016). Shareholder Protection, Ownership, and Dividends: Russian evidence. Emerging Market Finance and Trade, 52(10), 2414-33. https://doi.org/10.1080/1540496X.2015.1073991

Lintner, J. (1965). The Valuation of Risk Assets and the Selection of Risky Investments in Stock Portfolios and Capital Budgets. Review of Economics and Statistics, 47(1), 13-37. https://doi.org/10.1016/B978-0-12-780850-5.50018-6

Ma, J. Z., Ho, K. C., Lu, Y., \& Chu, C. C. (2018). Market Sentiment and Investor Overreaction: Evidence from New York Listed Asian Country Exchange Traded Funds. Emerging Markets Finance \& Trade, 54, 2455-2471. https://doi.org/10.1080/1540496X.2018.1464907

Markowitz, H. M. (1952). Portfolio Selection. The Journal of Finance, 7(1), 77-91. https://doi.org/10.1111/j.1540-6261.1952.tb01525.x

Masry, M., \& Menshawy, H. (2018). The Impact of Unsystematic Risk on Stock Returns in an Emerging Capital Markets (ECM's) Country: An Empirical Study. International Journal of Financial Research, 9(1), 189-202. https://doi.org/10.5430/ijfr.v9n1p189

Merton, R. (1987). A Simple Model of Capital Market Equilibrium with Incomplete Information. The Journal of Finance, 42(3), 483-510. https://doi.org/10.1111/j.1540-6261.1987.tb04565.x 
Moreno, D., \& Rodri'guez, R, (2013). Optimal Diversification Accross Mutual Funds. Applied Financial Economics, 23(2), 119-122. https://doi.org/10.1080/09603107.2012.711939

Morningstar.

Retrived

from https://my.morningstar.com/ap/FundTools/help/glossary.aspx?tab=morningstarrisk\&ismpf=0

Norman, N., Almsafir, M. K., \& Smadi, A. (2013). Comparative Study of Conventional and Shariah-Based Unit Trust Funds Performance of Public Mutual Berhad. Australian Journal of Basic and Applied Sciences, 7(9), 354-363.

Sharpe, W. F. (1964). Capital Asset Prices: A Theory of Market Equilibrium under Conditions of Risk. Journal of Finance, 19(3), 425-442. https://doi.org/10.2307/2977928

Soo, W. L. (2010). Relationship between Fund Performance and Characteristics of the Malaysian Unit Trust Funds. Singapore Management Review, 32(1), 29-43.

Tinic, S. M., \& West, R. R. (1984). Risk and Return: January vs. the Rest of the Year. Journal of Financial Economics, 13(4), 561-574. https://doi.org/10.1016/0304-405X(84)90016-3

Yong, P. S., \& Jusoh, R. (2012). Fund Characteristics and Fund Performance: Evidence of Malaysian Mutual Funds. International Journal of Economics and Management Sciences, 1(9), 31-43. 